\title{
Educação alimentar e nutricional como prática social
}

\section{Food and nutrition education as social practice}

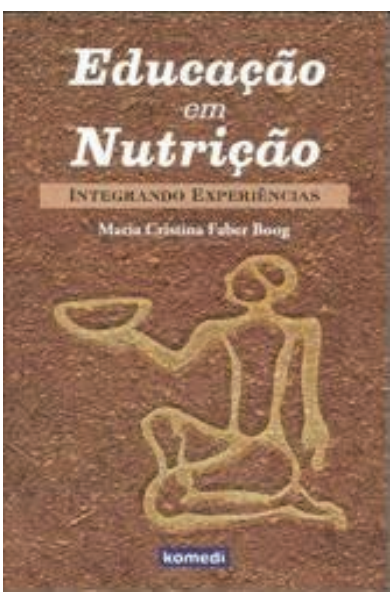

EDUCAÇÃO EM NUTRIÇÃO: INTEGRANDO EXPERIÊNCIAS Maria Cristina Faber Boog. $7^{\mathrm{a}}$ ed., Campinas: Komedi Editora, 2013. $268 \mathrm{p}$.

ISBN: 9788575826775

Hayda Alves'

Patrícia Walker²

' Curso de Pós-graduação em Saúde Pública. Escola Nacional de Saúde Pública Sergio Arouca ENSP/FIOCRUZ. Rio de Janeiro, RJ, Brasil.

${ }^{2}$ Curso de Pós-graduação em Gestão de Cuidado em Saúde. Universidade Federal Fluminense. Niterói, RJ, Brasil.

Correspondência / Correspondence Hayda Alves

E-mail:haydaenf@gmail.com
O livro Educação em Nutrição: integrando experiências, de Maria Cristina Faber Boog, traz os temas da alimentação e nutrição no escopo das intervenções em saúde como prática educativa, transformadora da realidade social, além de centrada no indivíduo e nas coletividades.

Neste sentido, a autora reafirma a necessidade de situar a educação alimentar e nutricional (EAN) no campo das ciências humanas e sociais, o que implica entender a alimentação como prática social - ou seja, constituída por elementos objetivos e simbólicos capazes de converter o ato alimentar em um fato social total. Como tal, conecta o individual de um lado, e o físico (ou fisiológico) e o psíquico, de outro ${ }^{1}$

Nesta perspectiva, alimentação se torna um dos determinantes da vida social, pois além de oferecer condições objetivas para sua manutenção, é importante para assegurar a constituição de vínculos necessários à sociabilidade humana e à reprodução social. Assim, o comportamento alimentar não se circunscreve ao que se come, como ou com quem se come. Envolve, ainda, um contrato social de identidades por meio da partilha implícita na tríade "dar, receber e retribuir". 2 Esta dimensão social da alimentação é um alicerce teórico importante ao campo, o qual Boog resgata de forma objetiva e clara para subsidiar reflexões e a efetivação de práticas educativas em alimentação e nutrição. 
Outro ponto forte da obra se concretiza na utilização da pedagogia de Paulo Freire para elevar a EAN como prática mais ampla do que uma simples transmissão de conhecimentos originados de guias e recomendações técnicas por parte dos profissionais de saúde aos usuários. Boog utiliza com maestria as teorias sociais e os conceitos da educação freireana para impulsionar reflexões no âmbito da alimentação e nutrição, e assim, elaborar estratégias de superação de um "pseudocientificismo" do campo, o qual tende a ignorar a importância do sujeito e de sua relação com o mundo por meio das práticas alimentares.

A autora defende, ainda, a importância do direito humano à alimentação como política pública. Para tanto, os profissionais de saúde devem se apropriar da EAN como educadores comprometidos com a transformação da realidade sanitária brasileira, em que pese o enfrentamento de doenças vinculadas às práticas alimentares. Assim, propõe ampliar ações de saúde a partir de um olhar mais humanizado para as práticas sociais, como a alimentação, no espaço institucional dos serviços de saúde e para além de suas paredes. Boog afirma a importância de se estender a alimentação para onde a vida se constrói, ou seja, onde as práticas alimentares são criadas e transformadas, como a casa, a escola, os espaços comunitários, entre outros.

Enfim, este manuscrito evoca a EAN como ação indispensável para a promoção da saúde, tendo em vista sua capacidade de apreender múltiplos determinantes sociais da saúde, como também alterar as repercussões do ato alimentar na produção social da saúde.

O livro é dividido em duas partes, cada uma com cinco capítulos, totalizando 268 páginas. Trata-se de uma obra subsequente ao livro Educação nutricional, uma referência nesse campo de conhecimento, também elaborado por essa pioneira da EAN em 1984, naquele momento em parceria com Denise Giacomo da Motta.

É importante ressaltar que o livro contém pressupostos teóricos estruturantes da EAN no campo das reflexões e das práticas, e também apresenta uma coletânea de experiências da autora e exemplos de práticas educativas que incitam a curiosidade e o desejo de experimentar.

Na primeira parte do livro, a autora tece uma rede explicativa sobre os propósitos e sentidos da EAN, considerando a alimentação como campo amplo e multidisciplinar. Nesse contexto, suas intervenções devem incorporar os distintos sentidos da vida em sociedade (social, histórico, político, econômico, etc.), além de conter os significados e as expressões que imprimem identidade às práticas alimentares nos diferentes níveis de abrangência (individual, familiar, comunitário, regional, entre outros).

No capítulo I, "Educação em nutrição: por que e para quê?”, a autora evidencia como as práticas alimentares possuem estreita relação com as políticas públicas. Neste sentido, o consumo alimentar pode ser considerado importante termômetro de políticas econômicas e sociais, bem como possibilita analisar a situação de saúde de uma população. Boog cita os inquéritos nacionais 
sobre o consumo alimentar como fontes importantes para elucidar a relação entre a alimentação e as condições de vida e saúde da população. Alerta, porém, que as reflexões sobre as práticas alimentares não se encerram neste aspecto. Para tanto, destaca a íntima relação da alimentação com a sociabilidade humana, ou seja, os modos de ser e viver em sociedade, o que a remete o ato alimentar a algo natural e prazeroso.

Na contramão de seu reconhecimento neste sentido, tem sido cada vez mais evidente a valorização de práticas alimentares disciplinadoras, ou seja, enquadradas em excessiva normatização dietética e individualização. A autora sugere que a EAN possa retomar o sentido humano da alimentação como prática social, intercambiada com os avanços e recomendações técnicas para uma vida mais saudável. Para tanto, mostra a necessidade de realçar o indivíduo e a família como focos da ação, em virtude de seu protagonismo na edificação de práticas saudáveis desde a infância.

Esta fase é importante para consolidar um conhecimento geracional sobre alimentação, o qual poderá ser rememorado na vida adulta e, possivelmente, tornar-se um elemento de resistência ao assédio midiático do consumo alimentar quantitativamente excessivo e qualitativamente inadequado. Portanto, as práticas alimentares saudáveis construídas desde a infância podem se configurar como anteparos importantes aos danos à saúde provocados por mudanças vivenciadas na vida adulta.

Por meio dessa análise, a autora destaca o potencial de transformação humana contido nas escolhas alimentares, assim como em qualquer outra prática social. Além disso, ressalta que as necessidades alimentares se modificam ao longo da vida. Dessa forma, "ensinar a comer" é atividade que não se restringe à infância, mas engloba todo o ciclo vital. A EAN deve ser uma prática orientada à singularidade humana nesse ciclo e também reflexiva à própria sociedade. Deve pautar-se em informações elaboradas a partir de conhecimentos científicos que produzem evidências orgânicas benéficas, contextualizadas em fatores de ordem simbólica que conferem sentido e imprimem identidade e movimento ao corpo (cultura, mitos, ritos, crenças, etc). Ou seja, não se trata de negar a importância do processo biológico no campo nutricional, ou ainda subutilizar os avanços verificados no campo das ciências do alimento. Estes devem ser aliados a uma compreensão da "alimentação pelo eixo do comportamento humano, como expressão de sentimentos, expressão cultural e prática social que reúne, firma e reafirma relações sociais e vínculos coletivos" (p .29).

Neste caminho, Boog afirma que a educação nutricional não é apenas um produto de conhecimentos científicos elaborados a partir de evidências clínico-laboratoriais. Nem se esgota em informação sobre aspectos técnicos e recomendações produzidas por meio de consensos de especialistas. Esse campo toca diferentes dimensões da vida, exigindo, portanto, o esforço de sistematizar estratégias de intervenção a partir da multidisciplinaridade. A junção dos elementos supracitados à valorização da cultura alimentar favorece o direito humano à alimentação. 
No capítulo II, "Contribuição da educação alimentar e nutricional para a promoção da alimentação saudável: conflitos e contradições”, a autora enuncia a importância da alimentação e nutrição na cena das políticas sociais nas últimas décadas, pautando-se em documentos fundantes da promoção da saúde, como também em elementos da engenharia institucional do governo federal voltados à construção de políticas e planos de ação no âmbito da alimentação, nutrição e segurança alimentar.

Nesta seção, Boog destaca que a EAN protagoniza importante eixo da promoção da saúde no Brasil, mas apesar dos avanços promovidos, ainda figura como campo de desafios e conflitos ligados à formação dos trabalhadores, a seu desenvolvimento no espaço institucional dos serviços, bem como a sua efetiva consolidação como política de Estado que se constrói na interseção dos campos da Educação e Saúde.

No capítulo seguinte, "Explorando a multidimensionalidade da alimentação", a autora apoia-se no paradigma da complexidade a partir de autores como Edgar Morin, para analisar os múltiplos sentidos da alimentação para a vida das pessoas. A alimentação conjuga desejos, heranças culturais e necessidades expressas por meio do comportamento alimentar, imprimindo complexidade ao fato alimentar. Nesse processo, os sujeitos se (res)significam por meio da alimentação como ato coletivo.

Segundo Boog, o ato de comer em companhia, a comensalidade, é uma das maiores expressões da dádiva em "dar, receber e retribuir", tornando-se, portanto, importante pilar das relações sociais. Neste sentido, a prática alimentar torna-se uma expressão de afeto, vínculo e cuidado. Portanto, a comensalidade deve ser considerada importante para a edificação de práticas de cuidado à saúde, especialmente no campo da EAN, bem como na elaboração de políticas de Estado que corporificam direitos. Por fim, a autora coloca como missão da EAN a criação de uma postura ética por parte de todos os setores e pessoas envolvidos no campo de alimentação.

No penúltimo capítulo desta parte, "Construindo práticas e valores”, Boog destaca como o tema da alimentação adquiriu evidência midiática. Porém, acrescenta que isso ocorreu a partir de uma série de informações contraditórias que tendem a beatificar ou demonizar o consumo de alguns alimentos. Tais extremos se alicerçam em dilemas que envolvem a busca de uma alimentação saudável, exótica, ou ainda, adequada para determinados padrões estéticos. Segundo a autora, atualmente se consome muita comida e informação sobre comida. Neste caminho, a alimentação tem se reafirmado como canal de expressão de inseguranças e de desejos humanos difusos, como melhorar o desempenho físico e a aparência, entre outros.

No capítulo que encerra esta parte do livro, intitulado "Da necessidade da educação em nutrição à necessidade de formar educadores", a autora ressalta a importância de valorizar a formação do nutricionista como educador. Nas últimas décadas, este papel ficou pouco evidente em decorrência de: falta de permeabilidade de conhecimentos sobre educação em cursos de 
graduação em Nutrição e pós-graduação oferecido aos nutricionistas; excessiva valorização do enfrentamento da pobreza e da insuficiência de renda como principais determinantes para uma alimentação saudável; e a "crença de que o papel do educador se esgota na comunicação de fatos da ciência da nutrição" (p. 94).

Durante todo o capítulo, a autora justifica a necessidade de o nutricionista realizar intervenções em saúde pautando-se em ideias desenvolvidas por pedagogos e filósofos da educação. Enfim, tratar o alimentar e o nutricional como atributos da educação.

Na segunda parte, Boog promove reflexões sobre a promoção da alimentação saudável e intervenções sobre problemas alimentares como campo de conhecimento e prática. Boog abre esta seção com o capítulo "Iniciando o trabalho em educação alimentar e nutricional: abrangências", onde denota a necessária abrangência das práticas de EAN realizadas junto às pessoas: indivíduos, famílias ou outros níveis de coletividade.

Neste sentido, essas práticas devem se pautar na troca de saberes, conhecimentos, experiências com vista ao restabelecimento, preservação e promoção integral da saúde. Por isso, sugere que o termo "aconselhamento alimentar e nutricional" é mais promissor do que outros empregados no mesmo sentido. Isto se justifica pelo fato de o primeiro se efetivar "como relação de ajuda apoiada nas teorias do aconselhamento, que privilegiam a empatia, a escuta, a compreensão dos problemas vivenciados, a avaliação das estratégias de enfrentamento empregadas nas mudanças empreendidas e os resultados, quer positivos, quer negativos" (p. 110). Destaca então o protagonismo de diferentes atores envolvidos no campo, dado seu potencial de transformação das próprias práticas alimentares, como das práticas de terceiros, além da influência desses sujeitos na replicação e modificação de conhecimentos adquiridos.

Boog reafirma a convergência dessa perspectiva de trabalho ao pensamento freiriano. Assim, a autora se apoia nos escritos de Paulo Freire para desenvolver a EAN no âmbito das pedagogias ativas, participativas, interativas e dialógicas com aspectos da realidade social. Por isso mesmo, tais práticas devem ser exercidas no âmbito comunitário em diferentes espaços, como escola, unidades de saúde, empresas, entre outros.

Boog considera que, ao passo que as Políticas Nacionais de Alimentação e Nutrição adentram distintos espaços sociais, tendem a incorporar diferentes coletividades e apontar ações mais efetivas, além das legitimadas socialmente.

No capítulo II, denominado "Pesquisar para compreender, compreender para interagir", Boog situa a importância da busca de conhecimentos científicos, populares, místicos, entre outros, para compreender o espaço da intervenção. Afirma ainda, que "a EAN não preconiza uma obediência passiva à dietas" (p. 115). Isto sugere que o indivíduo e seu espaço cotidiano estejam envolvidos nesta dinâmica. 
Neste caminho, a autora destaca que as ações educativas devem mobilizar as pessoas, seus sentimentos, suas certezas e, para tanto, devem ser desenvolvidas considerando elementos psíquicos, sociais e culturais conjugados aos aspectos técnicos da nutrição. Isso deve ocorrer com vista (re) formular valores, opiniões, representações - enfim, atitudes condizentes com as reflexões sobre as práticas alimentares.

Além de uma atenção individualizada, as práticas de EAN exigem ainda atentar para elementos de ordem econômica, social e cultural oriundos dos grupos de referenciais de cada pessoa, com a finalidade de se considerar aspectos ligados à produção, disponibilidade e aceitação de alimentos valorizados nas orientações nutricionais. Boog sugere que as práticas de EAN sejam precedidas de um diagnóstico educativo, no intuito de conhecer o sujeito da intervenção e valorizar a subjetividade das pessoas, aliado a indicadores vitais e métodos antropométricos classicamente empregados nas ciências da nutrição.

A autora destaca ainda que o campo de investigação qualitativa figura como fonte importante para ampliar a investigação no campo da nutrição, até pouco tempo restrita apenas aos tradicionais inquéritos alimentares. "A pesquisa qualitativa permite apreender a multidimensionalidade de um fenômeno e acessar a forma pela qual tal fenômeno se apresenta à consciência das pessoas” (p. 119). Isto possibilita entender além do que e o quanto se come, as razões pelas quais as pessoas agem e como agem - ou seja, aspectos do comportamento alimentar. Boog sugere conhecer e valorizar abordagens que captem e sejam capazes de produzir um conhecimento reflexivo aos problemas vividos e às intervenções propostas pelos profissionais. Por fim, afirma que os pressupostos construídos no campo da EAN à luz das metodologias qualitativas são promissores para iluminar o desenvolvimento de programas educativos de alcance local, regional ou nacional.

Já no capítulo III, "O que o educador ensina sem perceber que ensina", a autora realça as diferentes nuances do processo de aprendizado de profissionais e usuários envolvidos nesse campo. A prática educativa deve sempre privilegiar o encontro pedagógico, filosófico, afetivo, entre outras dimensões da relação estabelecida entre o educador e o educando. Isso não se faz apenas a partir do desenvolvimento de métodos e estratégias, mas exige uma tomada de posição ideológica que valoriza a escuta qualificada, a construção de relações horizontais de poder, além de atitudes abertas e promissoras ao diálogo.

Enfim, o educador deve partir do que mobiliza as pessoas à reflexão e à ação. Para evidenciar a intrínseca relação entre as práticas de EAN com a pedagogia, a autora expõe aspectos do pensamento de alguns autores clássicos que inspiraram diferentes abordagens ao processo educativo, como Skinner, Carl Rogers, entre outros. Em um item específico, mostra como tais abordagens podem subsidiar análises e intervenções singulares no campo. No entanto, é em Paulo 
Freire que autora encontra substrato para desenvolver práticas de EAN. Assim, parte da obra Educação como prática da liberdade para propor uma sistematização operacional ao desenvolvimento de práticas educativas. Para tanto, evoca a problematização freireana e a reflexão sobre as maneiras de ensinar, educar, saber ouvir e, sobretudo, compreender no âmbito da EAN.

Por fim, no capítulo IV, denominado "Vamos começar a agir", a autora ressalta o campo prático. Com base nos problemas no âmbito da EAN, as possibilidades teóricas e os caminhos elencados para seu encaminhamento, a autora incita o leitor à ação. Para tanto, torna-se necessário despir-se de atitudes arrogantes e autoritárias conjugadas ao uso do "avental branco" - símbolo de poder e distinção - que exigem obediência a dietas e prescrições de nutricionistas, médicos, enfermeiros, entre outros trabalhadores de saúde.

Como precaução, retoma o debate de que as práticas de EAN não podem estar circunscritas à prescrição de dietas, de que se deve buscar permanentemente a autonomia dos sujeitos. Além disso, tais práticas exigem tempo para a pessoa reconstruir, significar e integrar as informações dialogadas com o profissional na sua vida cotidiana. Partindo desses pressupostos, propõe etapas para elaborar atividades de EAN, sendo, resumidamente: (a) tomada de contato com o comportamento alimentar de forma a reconhecer fatores intervenientes e determinantes; (b) análise críticas desses fatores à luz de campos multidisciplinares; (c) compartilhamento de percepções e possibilidades de mudanças das práticas alimentares; (d) integração e harmonização destes valores aos novos comportamentos.

Ao longo do capítulo, a autora discute aspectos intrínsecos a cada uma das possibilidades de atuação profissional no campo da EAN, como:

(i) Aconselhamento: tomado como atendimento individual do problema alimentar e, sobretudo, da função de "ajuda” a ser desempenhada pelo profissional que se depara com o fato alimentar imerso no campo da complexidade. Isto demanda utilizar conhecimentos que não são propriamente o campo da nutrição que permitam apreender detalhes do fala do informante, no intuito de entender o problema apresentado e orientar as condutas profissionais numa perspectiva holística e integrativa de conhecimentos.

(ii) Abordagens com grupos: a autora sugere diferentes métodos originados de dinâmicas de grupos para impulsionar práticas de EAN pautadas no espírito de afetividade, solidariedade, compartilhamento de experiências e reflexão. Por conseguinte, sistematiza etapas nas abordagens com grupos, além de apresentar diferentes técnicas empregadas por educadores no campo da alimentação e nutrição. Assim, sugere o 
trabalho com reminiscências alimentares (memórias relacionadas ao fato alimentar); compartilhamento de experiências positivas; utilização da técnica de associações livres, a partir de palavras ou expressões vocalizadas pelos participantes; vivências alimentares com a valorização de órgãos dos sentidos (tato, paladar, olfato, visão e audição) e técnicas para conhecimento das expectativas e demandas do grupo, com a utilização de diferentes recursos audiovisuais. Ao discorrer sobre a utilização de cada uma das técnicas, propõe ainda uma teorização específica que justifica sua utilização. Após oferecer ao leitor um banquete de possibilidades, afirma que essas técnicas não devem constituir um fim em si, mas reforçar a criatividade dos educadores e aguçar o interesse dos educandos.

(iii) Programas educativos com abrangência comunitária: nesta seção, afirma as práticas de EAN devem ser pautadas no reforço da ação comunitária como um pressuposto da Promoção da Saúde, além de impulsionar a participação social, possibilitar a ampliação dos cenários de intervenção, incentivar o estabelecimento de parcerias entre diferentes atores e fortalecer do empowerment. O estímulo à participação comunitária é uma preocupação latente da autora para o desenvolvimento da intervenção nutricional, e também uma pré-condição para a criação e o bom andamento dos programas educativos públicos governamentais.

(iv) Educação por intermédio dos meios de comunicação: a autora destaca que a mídia, ou comunicação em massa não devem ser esquecidas pelos educadores no campo da alimentação e nutrição, mas considerados meios legítimos de difusão de informações, apesar de, por vezes, induzirem a comportamentos alimentares indesejáveis. Porém, acrescenta que isto reforça a necessidade de trazer a comunicação em massa para os debates promovidos no campo da alimentação e nutrição. Assim, sugere a utilização da mídia e seu poder de adentrar em diferentes lares e se inserir na vida dos sujeitos como um canal para as práticas de EAN, especialmente nas emissoras públicas e canais comunitários. Estes poderiam se tornar recursos utilizados pelos profissionais para ampliar o público das ações para a promoção da saúde. Além disso, Boog propõe o emprego do marketing com foco social. Ou seja, a comunicação de mensagens de caráter social para um grande público, empregando as atrativas (e sedutoras) técnicas de marketing comercial, a fim de estimular a prática de comportamentos saudáveis orientados por setores comprometidos com a saúde e o bem-estar da população (ministérios governamentais ou organizações da sociedade civil). 
Ao questionar se mídia e educação podem, efetivamente, se tornarem convergentes para um interesse social, a autora destaca alguns pontos importantes para o debate, como: o alcance midiático, a necessária cautela na difusão de mensagens educativas, a responsabilização implícita no estabelecimento de parcerias e, sobretudo, a necessária busca de respaldo de profissionais do campo da midiologia e também jurídico.

No último capítulo, "O que queremos fazer? O que conseguimos fazer?", a autora coloca em debate a intencionalidade subjacente às práticas alimentares e, por conseguinte, a necessidade de avaliar e validar determinada intenção por meio da análise dos resultados alcançados. Estes podem superar o que se esperava incialmente; ou ainda, se mostrarem insuficientes para as metas traçadas naquele momento. Mesmo resultados negativos são importantes dados da avaliação, não devendo ser tomados como fracasso, mas como pontos de fragilidade que demandam análise dos objetivos estabelecidos, dos conteúdos e métodos empregados, ou ainda, acenarem para a necessidade de elaborar um novo diagnóstico sobre o problema.

Dessa forma, destaca que a avaliação das práticas nutricionais exigem procedimentos metodológicos muito distintos daqueles utilizados na educação formal, em função de especificidades do campo da EAN e das práticas educativas em saúde. Ressalta que a avaliação deve possibilitar, por fim, a reelaboração dos objetivos da intervenção e o aprimoramento do trabalho do educador.

Embora a autora discuta a etapa de avaliação das intervenções realizadas, o livro não aprofunda este aspecto, deixando em aberto a discussão acerca da pactuação de mudanças e, consequentemente, sobre a participação nesse processo dos diferentes atores envolvidos em dada intervenção, como um atendimento individual, uma prática comunitária, entre outras.

Outro ponto importante, mas que, assim como o primeiro, não ofusca o brilhantismo da obra, reside no fato de o manuscrito carecer de uma análise crítica das práticas alimentares como reflexo de uma conjuntura socioeconômica produtora de iniquidades sociais com repercussões na saúde. ${ }^{3}$ As práticas alimentares podem constituir mecanismos de distinção social que fomentam a desigualdade, ou ainda, refletir iniquidades que historicamente tensionam a alimentação como direito humano de acesso universal. A reflexão sobre a justiça social e o enfrentamento de iniquidades de saúde figura como um dos pilares nos debates conduzidos pela Organização Mundial de Saúde. ${ }^{4}$ Incluir a práticas alimentares nesse debate emerge, na atualidade, como um tema latente e necessário.

Enfim, trata-se de uma leitura prazerosa e densa. É uma obra importante para professores, educadores populares, nutricionistas, enfermeiros, médicos - enfim, para todos os profissionais que têm como valor primordial a dimensão humana e a importância social de suas práticas. 


\section{Referências}

1. Lévi-Strauss, C. Introdução à obra de Marcel Mauss, In: Sociologia e Antropologia, vol. 2, São Paulo: EPU/Edusp; 1974. p. 37-184.

2. Mauss M. Ensaio sobre a dádiva. Marques, AF (tradução). Lisboa: Edições 70; 1988.

3. Commission on Social Determinants of Health. Closing the gap in a generation: health equity through action on the social determinants of health. Final Report of the Commission on Social Determinants of Health. Geneva, World Health Organization, 2008. [Acesso em 28 de mai. 2013]. Disponível em: http://www.who.int/social_determinants/thecommission/ finalreport/en/index.html.

4. The Commission on Social Determinants of Health Knowledge Networks, Lee, J.H. and Sadana, R. (ed.). Improving Equity in Health by Addressing Social Determinants. Geneva, WHO, 2011. 